\title{
Advancing gender equ(al)ity, lifting men's health: dealing with the spirit of our time
}

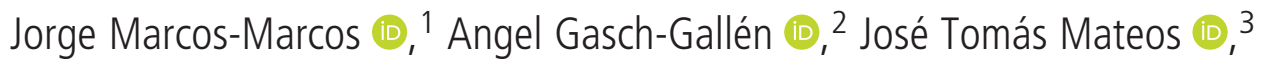 \\ Carlos Álvarez-Dardet (1) 4,5,6
}

${ }^{1}$ Department of Health Psychology, University of Alicante, Alicante, Spain ${ }^{2}$ Department of Physiatrist and Nursing, University of Zaragoza, Zaragoza, Spain

${ }^{3}$ Department of Nursing and Physiotherapy, University of Lleida, Lleida, Spain

${ }^{4}$ Public Health Research Group, University of Alicante, Alicante, Spain

${ }^{5}$ University Research Institute for Gender Studies, University of Alicante, Alicante, Spain ${ }^{6}$ Biomedical Research Networking Center for Epidemiology and Public Health (CIBERESP), Institute of Health

Carlos III, Madrid, Spain

Correspondence to

Jorge Marcos-Marcos, Department of Health

Psychology, University of Alicante, Edificio Polivalente III, 03690-Campus San Vicente Del Raspeig, Campus De San Vicente Del Raspeig, Ap.99. E-03080 Alicante, Spain; jorge.marcosmarcos@ua.es; marcosmarcos.jorge@gmail. com

Received 5 September 2019 Revised 4 February 2020 Accepted 25 July 2020

\section{Check for updates}

(c) Author(s) (or their employer(s)) 2020. No commercial re-use. See rights and permissions. Published by BMJ.

To cite: Marcos-Marcos J, Gasch-Gallén A, Mateos JT, et al. J Epidemiol

Community Health Epub

ahead of print: [please

include Day Month Year].

doi:10.1136/

jech-2019-213165

\section{ABSTRACT}

In this paper, we jointly address two connected issues that should be addressed together more purposefully within both public health policies and programmes: the health and well-being of men and boys, and the focus on equity versus equality from a gender perspective. Awareness of these issues has boosted the debate on the impacts of gender inequality on health and men's role within it. Although this essay is not intended as an in-depth review on the subject, we provide a brief approach to some critical factors interwoven in the process of achieving greater gender equality. We identify some of the challenges that may arise for both policy and new research that seek to assume a relational gender approach that also pays greater attention to men's health.

\section{INTRODUCTION}

There is a growing recognition that public health must address the quality of human interpersonal relationships. The 2030 Agenda for Sustainable Development adopted by all the United Nations member states offers a common framework through which to deal with a set of challenges that are related to this matter either directly or indirectly. At the root of this issue is gender; a social construct rooted in the characteristics shaping norms, roles and values considered appropriate for men and women in a given time and context. ${ }^{1}$ Albeit without losing sight of the interrelationships between sex and gender, ${ }^{2}$ the adoption of a relational approach takes on special significance in the formulation of gender policies and interventions. ${ }^{3}$ This involves comprehensively analysing the ill-health processes in the context of the interactions between men and women, alongside their social positions within a multidimensional structure that interconnects socio-economic, affective, symbolic and power relations and operates at individual, interpersonal and institutional levels. ${ }^{4}$

This essay addresses two issues that must be jointly addressed more purposefully within public health policies, programmes and interventions: (a) the health and well-being of men and boys; (b) the equity versus gender equality agenda. While the former issue has increasingly achieved a greater resonance in society, ${ }^{5}$ the latter lags behind and continues to be treated as a minor social issue. ${ }^{7}$ However, there is an increasing corpus of evidence in favour of addressing and evaluating the confluence of both issues, ${ }^{8} \quad 9$ especially after strengthening the explanatory framework for gender inequalities in health. ${ }^{10}$

The fact that the gender perspective and public health share a social dimension highlights an opportunity to give prominence to the determinants of health in any discussion of equity and social justice. Awareness of these issues boosts the debate on the impacts of gender inequality on health and men's role within it. ${ }^{11}$ Although this essay is not intended as an in-depth review of the subject, we provide a brief approach to some critical factors interwoven in the process of achieving higher levels of gender equality. This also requires the consideration of a number of challenges that may arise for research, which are in tune with the gender-responsive approach promoted by extant policies.

\section{MEN, BEHAVIOURS AND HEALTH: THE DARK SIDE OF PRIVILEGES BEHIND GENDERED NORMS AND EXPECTATIONS}

Research on men's health experienced a significant change when masculinities_-differing ways of being a man-began to be understood fundamentally as configurations of collective practices, avoiding limiting gender analysis to the examination of individual personality traits. ${ }^{12}$ In this sense, the emergence of the concept of hegemonic masculinity emphasised the existence of a gendered dominant construct characterised by the appreciation of attitudes of resistance, invulnerability or aggressiveness, intimately connected to emotional control and/or the adoption of risks. ${ }^{13}$ From this perspective, the analysis of these idealised attitudes and patterns of practice suppose a dominant positioning that subordinates femininities but also other forms of masculinity. ${ }^{14}$ This allows us to interpret this concept as a key political mechanism to legitimise hierarchical power relations within our societies. Similarly, it also facilitates the recognition that the meanings of masculinity are subject to change over time. Analysing these changes is key because they reveal how the agency of women and the gender struggles, including those of subordinate masculinities, are impacted by dominant forms. This highlights the interactions between masculinities, underscoring the notion that hegemonic masculinity must be defined as a process, rather than merely as a set of attributive traits.

Despite the advances that are taking place globally, overall men still maintain an advantageous social position, which has nothing to do with purely economic inequalities, but also with factors related to political empowerment and decision-making 
capacity. ${ }^{15}$ However, one of the paradoxes identified by contemporary literature is the negative aftermath of privileges, rooted in a patriarchal social system that differentiates and stratifies human beings in favour of men. ${ }^{16}$ Even though the literature shows a plurality of masculinities, and how the analysis of gender identities relates in multiple ways to health behaviours, ${ }^{17-19}$ many studies reveal that the gendered social and political advantages granted to men often result in patterns of socialisation that lead to unhealthy practices that can ultimately damage their health. ${ }^{20} 21$ This has contributed, among other aspects, to paying greater attention to their shorter life expectancy and the significant differences between countries and their populations. As an illustrative example, within the WHO European Region, the average life expectancy among men themselves varies within the region of $64.7-81.2$ years of age, attributing $86 \%$ of all male deaths to injuries and non-communicable diseases. ${ }^{22}$

Research shows that the most significant gender disparities in morbidity and mortality are due to behavioural differences between men and women, ${ }^{23}{ }^{24}$ which also reflect how both define and prioritise their health. ${ }^{10}$ In men, disease-coping strategies and mortality rates are also related to having less access than women to health services, especially in primary care, as well as having lower participation rates in preventive or health-promoting initiatives, ${ }^{6} 23$ which also leads to lower health literacy. ${ }^{25} 26$ Thus, the social expectations and stereotypes regarding behaviours that are considered appropriate are embedded within a gender order; an illustrative example is that showing no sign of vulnerability is considered a trait of manhood, leading many men to not ask for help. ${ }^{21} 27$ As a result, gender establishes many priorities that act as barriers to accessing health resources, which increases the risk of premature mortality in men. ${ }^{24} 28$ The literature has tended to largely explain the differences in men's health taking into account the consequences of their lifestyles, often associated with individual decisions and issues of self-control and personal responsibility; however, this analysis minimises the impact of socio-economic and political structures on men. ${ }^{29} 30$ The increasing attention to how gender is related to equity has broadened the point of view towards factors like social support, academic performance or employability, and their influence on men's commitment to healthcare services or preventive programmes. $^{31}$

\section{HEALTH BEHIND GENDER EQUITY VERSUS GENDER EQUALITY}

Most studies that have approached the association between health outcomes and gender equality have tended to use composite or individual measures of socio-economic status, political participation or sexual and reproductive rights, highlighting how gender inequity gives rise to differential health risks for men and women. ${ }^{9}$ This has also helped to conceptualise equality in a broader sense, amplifying its possibilities of measurement and application to health research, but maintaining its emphasis on power relations. ${ }^{3}$ This is why tolerance to violence among men is considered one of the single most significant issues when analysing the relationship between gender and health. For instance, the crosssectional ecological study developed by Stanistreet et $a l^{32}$ identified that the higher the rate of female homicide, the higher the rate of premature mortality in men; that is, the same practices that represent men's capacity to oppress women and promote their own interests systematically damage men themselves.

Although the literature shows the complex relationship that exists between the construction and performance of masculinities in regards to intimate partner violence (IPV), the hegemonic forms of traditional masculinity have been more closely associated with male perpetration. ${ }^{33}$ In this sense, the research underlines how, in the context of IPV, many men are seeking to construct alternative forms of masculinity. ${ }^{35-37}$ To this end, we must call attention to the fact that gender equality measures are associated with a lower risk of violent death in men themselves, as in the case of Holter's study. ${ }^{38}$ All this underlines, in line with the systematic review performed by King et a $l^{9}$ that promoting gender equality, for example, increasing men's involvement in the domestic sphere, not only has a positive impact on women's health but on men's health too; mainly in relation to the adoption of healthier behaviours and increasing health literacy, including self-care. In any case, this should not prevent one taking into consideration that (a) the levels of gender equality vary between regions, thereby shaping the sociocultural settings' differential impact on health ${ }^{8}$ and (b) the associations between health outcomes and gender equality do not always shape a linear relationship, at least in the first instance. ${ }^{39}$ At the heart of this issue lie the socio-economic dynamics and policies that have driven women to incorporate themselves into traditionally 'masculine' roles, while men have not had the same incentives to take part in responsibilities considered traditionally 'feminine'. ${ }^{10} 40$

If we look at morbidity patterns in the context of the convergence hypothesis, the decrease in the levels of gender inequality may in the foreseeable future lead to a reduction in the health outcomes between men and women because the adoption of risk behaviours tends to be more closely aligned. ${ }^{9}{ }^{41}$ However, the distribution of gender roles has not developed synergistically, highlighting the differences in remunerated work and informal caring responsibilities for families and dependents, all of which have a greater negative impact on women's health. ${ }^{10} 42$

The limited participation of men within the reproductive sphere can be associated with the social incentives posed by the male breadwinner model. These expectations expose men to increased occupational health risks. In situations such as a loss of employment or transition to retirement, men experience a greater negative impact on their mental health and lifestyles and an increase in their risk of cardiovascular diseases. ${ }^{43}$ From this perspective, equality must also involve an expansion role for men, not just for women; an axis on which the analysis of differential effects that hide behind the gender inequality processes must pivot. ${ }^{41}$

Focusing attention on the relationship between equality and health should also contribute to broadening the explanatory framework of masculinities. The primary approach has tended to analyse the health of men based on their individual behaviours. ${ }^{645}$ Although this is a useful starting point, we need to frame such explanations about risk factors within a broader range of social mechanisms, including gender policies and their connection to health outcomes. ${ }^{546}$

Developing an explanatory hypothesis on the differences and inequalities in health requires an in-depth analysis of local contexts. We should therefore be aware that the characteristics of material infrastructure and collective social functioning are consistently embodied in socio-economic and political enclaves. Furthermore, it requires that discussions on biological factors are open to exploring the complexity of bio-social interactions. ${ }^{2} 11$ This is precisely what has contributed to furthering the development of eco-epidemiological approaches, recognising the causes of ill-health on multiple levels and promoting the advancement of both qualitative and quantitative methods to research them. ${ }^{47}$ This approach supports the incipient development within the epidemiology of the intersectionality concept, initially formulated by Kimberlé Crenshaw. ${ }^{48}$ This implies starting from the premise that in people's lives there are always multiple social and political identities at play (eg, gender, occupational class, sexuality, disability, among others), which, as axes of inequality, might combine to 
Table 1 Key areas for action and initiatives to improve men's health connected to the equality agenda

Supporting the role of men in achieving gender equality

- Emphasise the role of men in achieving gender equality and in the health and well-being of men and women.

- Recognise intersections between gender (masculinities) and social determinants of health: risk exposure in specific groups of men

- Collaboration between the health sector and civil society: men involved in fatherhood and caregiving.

- Target adolescents to address the change in the health impact of discriminatory gender norms and roles.

Challenging the gender imbalance in paid and unpaid care

- Identify and combat the gender imbalance in paid and unpaid care (gender-equitable attitudes and behaviours).

- Implement gender-transformative policies in the working conditions of the health workforce as a way of demonstrating the leadership of health systems in promoting gender equity in the workplace.

- Address institutional gender discrimination: employment, social protection and health insurance policies.

- Assess the health impact of parental leave policies and flexible working arrangements that support the role of men as fathers and guardians.

\section{Engaging men in violence prevention}

- Interventions that focus on life skills, parenting, academic enrichment, social development and safety in schools, especially multi-component programmes.

- Address the likelihood that children and adolescents will become violence victims/ perpetrators later in life.

- Recognise the role of men as active agents to challenge the normalisation of violence, involving them in programmes aimed to eliminate violence against women.

Men Engage Alliance is an alliance of national networks, non-governmental organisations and UN partners around the world. Their purpose is to provide advocacy about engaging men and boys in gender equality and promoting initiatives and practices to achieve it (menengage.org). Men Engage Alliance promote sexual and reproductive health and rights, focusing on HIV and AIDS and combating homo/transphobia. They also act against gender violence and violence between men and boys. They advocate for equality policies and men's positive involvement in maternal and child health.

MenCare is a global fatherhood campaign coordinated by Promundo and Sonke Gender Justice in more than 50 countries. They aim to promote men's involvement as equitable, nonviolent fathers and caregivers to achieve family well-being, gender equality and better health for mothers, fathers and children, supporting women's social and economic equality (men-care.org). The 'Program $\mathrm{P}^{\prime}$ and 'MenCare+' programmes provide concrete strategies and activities to engage men globally in active fatherhood and as partners in maternal, newborn and child health. They advocate for policies of equality in paid parental leave and ending corporal punishment. They also provide media campaigns and the State of the World's Father that show key global data on fatherhood.

Promundo is a global consortium with member organisations in the United States, Brazil, the Democratic Republic of the Congo, Portugal and Chile. They aim to advance gender equality and create a world free from violence by engaging men and boys in partnership with women, girls and individuals of all gender identities. (promundoglobal.org). 'Program H', carried out since 2002 by Promundo and partners, aims to promote the critical reflection of rigid norms related to manhood and encourages the transformation of stereotypical roles associated with gender. 'Program $\mathrm{H}^{\prime}$ is based on group education activities about help changing attitudes, adjusting coping mechanisms and introducing healthier ways to deal with conflict.

Sharing responsibility for sexual and reproductive health

- Promote comprehensive sexuality education to transform gender norms that lead men to engage in high-risk behaviours and practices that also contribute to perpetuating discrimination and harmful practices against women and girls.

- Involve adolescent boys and girls in policies, programmes and services related to sexuality education, sexual and reproductive health, addressing gender norms and negative stereotypes related to these sexual health issues and rights.

- Support evidence-based programmes and interventions to increase men's use of sexual and reproductive health services.

Engender Health is an international non-profit organisation based in the USA whose aim is to implement high-quality, gender-equitable programmes that advance sexual and reproductive health and rights (engenderhealth.org). Their 'Men As Partners' (MAP) programme works with men to play constructive roles in promoting gender equity and health in their families and communities. MAP activities include confronting harmful stereotypes of what it means to be a man, enhancing healthcare facilities' capacity to provide men with quality care, leading local and national public education campaigns and building national and international advocacy networks.

create unique modes of discrimination. ${ }^{3}$ This leads to a conceptual change in the way we understand the identities and their interactions, exploring more deeply the causes of the causes underlying health inequalities. ${ }^{10} 49$

\section{PATHS ARE MADE BY WALKING: HEALTH, EQU(AL)ITY AND THE SPIRIT OF OUR TIME}

The great attention to gender in public health ${ }^{8} 1049$ has supplied increasingly robust knowledge about issues such as the gender biases in epidemiological research ${ }^{50}$ or the similarities and the differences between women and men, but also within themselves. ${ }^{12} 51$ Consequently, since men and women as a group differ by socio-economic status, age and other social categories, it is necessary to adopt a lifecycle approach to extend the causal chain of explanations linked to the analysis of health and well-being processes. ${ }^{52}$ This facilitates a better understanding of the everyday circumstances and experiences that produce the differing morbidity and mortality patterns observed in different groups of men and women. ${ }^{49}{ }^{53}$ However, broader comprehension of the interactions between sex and gender in different contexts is still required; that is: (a) how gendered sociocultural practices influence sex differences in biology and (b) how biological sex influences socio-cultural gender. ${ }^{2}$
The tendency to address men's health as if they were a homogeneous group contributes to not making visible other more positive models of masculinity, and to exclude men who experience non-normative identities. ${ }^{5} 31$ Thus, when taking a gender perspective on men's health research, a stronger focus on heterogeneity is vital. ${ }^{12}{ }^{54}$ From this viewpoint, we can more critically analyse the complexities of gender identity in relation to lifestyles and the adoption/avoidance of risks. ${ }^{6} 1852$ In addition, we must deepen our understanding concerning how the gender order of privilege and oppression influences the social practices and subsequent health outcomes, taking into account the intersection of gender and other axes of inequality, for example, lower socio-economic status, ethnicity, disability, rurality, not only of men over women but also among different population groups of men. ${ }^{22}$ The National Men's Health Policy developments in Ireland, Australia, Iran and Brazi ${ }^{55-58}$ are pioneering initiatives implemented to try and more effectively address health conditions that are unique or common among men from the perspective of social determinants of health. ${ }^{59}$ The approval of the 'Strategy on the health and well-being of men in the WHO European Region', 22 complementarily developed to the strategy on women's health, can be considered a new substantial step forward by taking a relational perspective on gender. 
Among other implications, the increase in attention to masculinities and men's health should serve to revitalise the need to: (a) develop more comprehensive research on gendered risk-taking during the life course; (b) promote and disseminate the evaluation of policies, programmes and interventions with a gendertransformative approach, that is, that addresses the causes of gender-based inequalities and works to transform harmful gender roles, norms and power relations; (c) reinforce a health approach that challenges negative gender stereotypes and contributes to building more equitable normative codes; and (d) empower health systems to be more gender-responsive, that is, consider men and women's specific needs. These guidelines provide a roadmap to improve the health of all men by achieving higher social levels of health equity and gender equality. Specifically, to cope with the challenge ahead and to integrate gender equality into mainstream health, we should prioritise four intervention areas: (1) supporting the critical role of men in achieving gender equality; (2) challenging the gender imbalance in paid and unpaid care; (3) engaging men in violence prevention; and (4) sharing responsibility for sexual and reproductive health. ${ }^{9} \quad 22 \quad 24 \quad 52$ Following this gender-relational approach, table 1 illustrates the key areas for action along with some initiatives to improve men's health connected to the equality agenda.

Strengthening the development of these lines of action requires public health policymakers and researchers to work in a more determined and pragmatic way to implement gendered and equ(al)ity-driven approaches. However, this involves not only implementing actions and measures to compensate for the social disadvantages that prevent women and men from operating on a level playing field, but also promoting the equal enjoyment of socially valued goods, resources and opportunities by different groups of women and men.

\section{CONCLUSION}

This paper advocates for a comparative and collaborative perspective in approaching men and women's health. Advancing work focusing on health from a relational gender perspective requires not only improving the dissemination of the benefits but also of the responsibilities. There is a great opportunity opening up before us: to jointly address the achievement of greater gender equality by developing the important role of men in achieving it. Although this article presents a limited review of the literature, it allows us to point out that to reach this goal we need gender-transformative programmes and interventions that approach the differences and inequalities in health that exist among men and women. This is a priority that we should not consider contrary but should converge with another: we need further development of initiatives in different regions and countries addressing men and boys according to the specific identified health needs throughout their lifecycle and considering the plurality of masculinities.

Twitter Jorge Marcos-Marcos @j_marcosmarcos, Ángel Gasch-Gallén @GaschAngel, José Tomás Mateos @jtmateos, Carlos Álvarez-Dardet @CAlvarezdardet.

Acknowledgements The authors are grateful for all the comments and suggestions received by the reviewers of the Journal. The authors would also like to thank Isabel Yordi Aguirre (WHO Regional Office for Europe) for her comments on earlier drafts of this paper.

Contributors JMM and CAD conceived the paper. JMM wrote the draft with input from AGG, JTM and CAD. All authors reviewed the manuscript and approved the final version.

Funding This paper received no specific grant from any funding agency in the public, commercial, or not-for-profit sectors.

Competing interests None declared.
Patient consent for publication Not required.

Provenance and peer review Commissioned; externally peer reviewed.

Data availability statement There are no data in this work. All data relevant to the study are included in the article or uploaded as supplementary information.

\section{ORCID iDs}

Jorge Marcos-Marcos http://orcid.org/0000-0002-7607-6672

Angel Gasch-Gallén http://orcid.org/0000-0002-3087-8899

José Tomás Mateos http://orcid.org/0000-0002-1419-1093

Carlos Álvarez-Dardet http://orcid.org/0000-0003-3530-7451

\section{REFERENCES}

1 Phillips SP. Defining and measuring gender: a social determinant of health whose time has come. Int J Equity Health 2005;4:11.

2 Krieger N. Genders, sexes, and health: what are the connections: and why does it matter? Int J Epidemiol 2003;32:652-7.

3 Hammarström A, Johansson K, Annandale E, et al. Central gender theoretical concepts in health research: the state of the art. J Epidemiol Community Health 2014;68:185-90.

4 Connell RW. Gender, health and theory: conceptualizing the issue, in local and world perspective. Soc Sci Med 2012;74:1675-83.

5 Schofield T, Connell RW, Walker L, et al. Understanding men's health and illness: a gender-relations approach to policy, research, and practice. J Am Coll Health 2000;48:247-56.

6 Robertson S. Understanding men and health: masculinities, identity and well-being. London (UK): Open University Press, 2007.

7 Horton R. Offline: gender equality: the neglected SDG for health. Lancet 2015:386:1928.

8 Backhans MC, Burström B, Lindholm L, et al. Pioneers and laggards: is the effect of gender equality on health dependent on context? Soc Sci Med 2009;68:1388-95.

9 King TL, Kavanagh A, Scovelle AJ, et al. Associations between gender equality and health: a systematic review. Health Promot Int 2020;35:27-41.

10 Sen G, Östlin P. Gender inequity in health: why it exists and how we can change it. Glob Public Health 2008;3:1-12.

11 Connell R. Confronting equality: gender, knowledge and global change. Cambridge (UK): Polity Press, 2011.

12 Connell R. Gender. Cambridge (UK): Polity Press, 2002.

13 Hearn J, Nordberg M, Andersson K, et al. Hegemonic masculinity and beyond: 40 years of research in Sweden. Men Masc 2012;15:31-55.

14 Connell RW, Messerschmidt JW. Hegemonic masculinity: rethinking the concept. Gender Soc 2005;19:829-59.

15 World Economic Forum. Global gender gap report 2020. Switzerland, 2019. Available http://www3.weforum.org/docs/WEF_GGGR_2020.pdf (accessed 22 Jan 2020).

16 Scott-Samuel A. Patriarchy, masculinities and health inequalities. Gaceta Sanitaria 2009;23:159-60.

17 de Visser RO, McDonnell EJ. "Man points": masculine capital and young men's health. Health Psychol 2013;32:5-14.

18 Mahalik JR, Burns SM, Syzdek M. Masculinity and perceived normative health behaviors as predictors of men's health behaviors. Soc Sci Med 2007;64:2201-9.

19 O'Brien R, Hunt K, Hart G. 'It's caveman stuff, but that is to a certain extent how guys still operate': men's accounts of masculinity and help seeking. Soc Sci Med 2005:61:503-16.

20 Evans J, Frank B, Oliffe JL, et al. Health, illness, men and masculinities (HIMM): a theoretical framework for understanding men and their health. J Men's Health 2011:8:7-15.

21 Courtenay WH. Constructions of masculinity and their influence on men's well-being: a theory of gender and health. Soc Sci Med 2000;50:1385-401.

22 World Health Organization. Regional office for Europe. The health and well-being of men in the WHO European region: better health through a gender approach. Copenhagen: World Health Organization, Regional Office for Europe, 2018.

23 European Commission. The state of men's health in Europe. Brussels: European Commission, 2011.

24 Pan American Health Organization. Masculinities and health in the region of the Americas. Washington, DC: PAHO, 2019.

25 Peerson A, Saunders M. Men's health literacy in Australia: in search of a gender lens. Int J Men's Health 2011;10:111-35.

26 Oliffe JL, Rossnagel E, Kelly MT, et al. Men's health literacy: a review and recommendations. Health Promot Int 2019; daz077.

27 Schrock D, Men SM. Masculinity, and manhood acts. Annu Rev Sociol 2009:35:277-95.

28 Kavanagh SA, Shelley JM, Stevenson C. Does gender inequity increase men's mortality risk in the United States? A multilevel analysis of data from the national longitudinal mortality study. SSM Popul Health 2017;3:358-65.

29 Baker P, Dworkin SL, Tong S, et al. The men's health gap: men must be included in the global health equity agenda. Bull World Health Organ 2014;92:618-20. 
30 White A, Seims A, Cameron I, et al. Social determinants of male health: a case study of leeds, UK. BMC Public Health 2018;18:160.

31 Robertson S, Kilvington-Dowd L. Masculinity and men's health disparities: conceptual and theoretical challenges. In: Griffith DM, Bruce MA, Thorpe Jr R, eds. Men's health equity: a handbook. New York: Routledge, 2019: 10-26.

32 Stanistreet D, Bambra C, Scott-Samuel A. Is patriarchy the source of men's higher mortality? J Epidemiol Community Health 2005;59:873-6.

33 Fulu $E$, Jewkes R, Roselli $T$, et al. Prevalence of and factors associated with male perpetration of intimate partner violence: findings from the UN multi-country cross-sectional study on men and violence in Asia and the pacific. Lancet Global Health 2013;1:e187-207.

34 Jewkes R, Flood M, Lang J. From work with men and boys to changes of social norms and reduction of inequities in gender relations: a conceptual shift in prevention of violence against women and girls. Lancet 2015;385:1580-9.

35 lyer P. 'Due to all this fear, we're getting less freedom': young people's understandings of gender and sexual violence in New Delhi, India. Gend Educ 2019;31:222-39.

36 Goicolea I, Öhman A, Salazar Torres M, et al. Condemning violence without rejecting sexism? Exploring how young men understand intimate partner violence in Ecuador. Glob Health Action 2012;5:18049.

37 Salazar M, Negotiating Masculinity ÖA. Violence, and responsibility: a situational analysis of young nicaraguan men's discourses on intimate partner and sexual violence. J Aggress Maltreat Trauma 2015;24:131-49.

38 Holter ØG. "What's in it for men?": old question, new data. Men Masc 2014;17:515-48.

39 Månsdotter A, Deogan C. Further gender equality: is it good or bad for sexual health? J Gender Stud 2016;25:294-302.

40 England P. The gender revolution: uneven and stalled. Gender Soc 2010;24:149-66.

41 Backhans MC, Lundberg M, Månsdotter A. Does increased gender equality lead to a convergence of health outcomes for men and women? A study of Swedish municipalities. Soc Sci Med 2007;64:1892-903.

42 Krantz G, Berntsson L, Lundberg U. Total workload, work stress and perceived symptoms in Swedish male and female white-collar employees. Eur J Public Health 2005;15:209-14.

43 Lundin A, Falkstedt D, Lundberg I, et al. Unemployment and coronary heart disease among middle-aged men in Sweden: 39243 men followed for 8 years. Occup Environ Med 2014;71:183-8.
44 Noone JH, Stephens C. Men, masculine identities, and health care utilisation. Sociol Health IIIn 2008;30:711-25.

45 Dolan A. 'Men give in to chips and beer too easily': how working-class men make sense of gender differences in health. Health (London) 2014;18:146-62.

46 Robertson S, Gough B, Robinson M. 2018. Masculinities and health inequalities within neoliberal economies. In: Walker C, Roberts S, eds. Masculinity, labour, and neoliberalism. Cham: Springer International Publishing: 311-34.

47 March D, Susser E. The eco- in eco-epidemiology. Int J Epidemiol 2006;35:1379-83.

48 Crenshaw K. Mapping the margins: intersectionality, identity politics, and violence against women of color. Stanford Law Rev 1991;43:1241.

49 Doyal L. Gender equity in health: debates and dilemmas. Soc Sci Med 2000;51:931-9.

50 Ruiz-Cantero MT, Vives-Cases C, Artazcoz L, et al. A framework to analyse gender bias in epidemiological research. J Epidemiol Community Health 2007;61:ii46-53.

51 Green MA, Evans CR, Subramanian SV. Can intersectionality theory enrich population health research? Soc Sci Med 2017:178:214-6.

52 Marcos-Marcos J, Mateos JT, Gasch-Gallén A, Álvarez-Dardet C. Men's health across the life course: A gender relational (critial) overview. J Gend Stud 2019.

53 Popay J, Williams G. Equalizing the people's health: a sociological perspective. In: Gabe J, Calnan M, eds. The new sociology of the health service. London: Wiley/ Routledge, 2009: 232-54.

54 Smith JA, Richardson N, Robertson S. Applying a genders lens to public health discourses on men's health. In: Gideon J, ed. Handbook on gender and health. Northampton: Edwar Elgar Publishing, 2016: 117-33.

55 Costa Lima D, Schwarz E. The Brazilian national policy of comprehensive healthcare to men. Int J Men's Soc Community Health 2018;1:e36-49.

56 Department of Health and Ageing Australia. National male health policy: building on the strengths of Australian males. Canberra, Australia: Australian Government, 2010.

57 Department of Health and Children Ireland. National men's health policy 2008-2013: working with men in Ireland to achieve optimum health \& wellbeing. Dublin (Ireland): Dept. of Health and Children, Hawkins House, 2008.

58 Esmailzade H, Mafimoradi S, Elmira Mirbahaeddin S, et al. Devising a national men's health policy document: the current challenges to men's health in Iran. Int J Men's Health 2016;15:174.

59 Richardson N, Smith JA, Robertson S, et al. Global men's health policy. In: Griffith D, Bruce M, Thorpe Jr R, eds Men's health equity. New York: Routledge, 2019: 203-24. 